\title{
KELAS KESESUAIAN LAHAN UNTUK PENGEMBANGAN TANAMAN VANILI DI KECAMATAN BALANTAK KABUPATEN BANGGAI
}

\author{
Muliyanto Riswanto ${ }^{1)}$, Mihwan Sataral ${ }^{2 *}$, Hertasning Yatim ${ }^{3)}$, Hidayat A Katili ${ }^{4)}$ \\ 1) ${ }^{\left.\left.2)^{*}, 3\right), 4\right)}$ Program Studi Agroteknologi, Fakultas Pertanian, Universitas Tompotika Luwuk \\ e-mail : muliantomoidadu961@gmail.com ${ }^{1}$, mihwansatara187@ gmail.com ${ }^{2)^{*}}$, \\ hertasningyatim70.hy@gmail.com ${ }^{3)}$, hidayat.katili11@gmail.com ${ }^{4)}$
}

\begin{abstract}
ABSTRAK
Kajian evaluasi lahan perlu dilakukan untuk memaksimalkan penggunaan lahan yang berpotensi untuk pengembangan komoditi perkebunan. Penelitian ini bertujuan untuk mengetahui karakteristik dan kesesuaian lahan untuk pengembangan tanaman Vanili (Vanilla planifolia) serta mengethui faktor pembatas apakah yang menjadi kendala dalam pengembangan tanaman Vanili di Desa Mamping Kecamatan Balantak. Penelitian ini dilaksanakan di Desa Mamping Kecamatan Balantak dengan metode indeks lahan menurut Storie (1985), dimana $\mathrm{S}=\mathrm{A} \times \mathrm{B} \times \mathrm{C} \times \mathrm{Xn}$. Hasil penelitian untuk Kelas kesesuaian lahan (KKL) pedon (Profil-1, Profil-2) termasuk dalam kategori kelas 3 (sedang), sehingga dapat diarahkan untuk pengembangan tanaman Vanili, namun membutuhkan pengelolaan lahannya (pemupukan) yang teratur. Pada Profil-3 perlunya penataan dalam olah tanah agar menjaga kestabilan dari suatu lahan untuk tanaman Vanili jangka panjang. Selanjutnya faktor pembatas untuk penggunaan lahan tanaman Vanili di pedon (Profil-1, 2 dan 3) yakni lapisan atas yang bertekstur sedang dan kurangnya kandungan bahan organik, $\mathrm{N}$ dan $\mathrm{K}$, bertekstur liat yang tinggi serta drainase tanah yang kurang baik.
\end{abstract}

Kata kunci : Kesesuaian lahan, vanili.

\section{PENDAHULUAN}

Perencanaan penggunaan lahan merupakan penilaian yang sistimatik terhadap lahan untuk mendapatkan alternatif penggunaan lahan dan memperoleh opsi yang terbaik dalam memanfaatkan lahan agar terpenuhi kebutuhan manusia dengan tetap menjaga agar lahan tetap dapat digunakan pada masa yang akan datang (Bagu 2012). Perencanaan penggunaan lahan pertanian dapat dilakukan melalui evaluasi kesesuaian lahan (Rehmana et al, 2020). Dalam evaluasi lahan perlu dipahami istilah-istilah yang digunakan, baik yang menyangkut keadaan sumberdaya lahan, maupun yang berkaitan dengan kebutuhan atau persyaratan tumbuh tanaman. Evaluasi lahan juga merupakan bagian dari proses penggunaan tata guna lahan, klasifikasi kesesuaian atau kemampuan lahan dikelompokkan lahan berdasarkan kesesuaiannya dan kebutuhan akan lahannya untuk tujuan penggunaan tertentu (Widiatmaka, 2012). Sistem evaluasi lahan yang berkembang selama ini menggunakan berbagai pendekatan, antara lain sistem perkalian parameter, penjumlahan, dan system matching atau mencocokkan antara kualitas/karakteristik lahan (Land Qualities/Land Characteritics) dengan persyaratan tumbuh tanaman (Land Use Requirement) (Djainudin et al 2011).

Kebutuhan lahan yang semakin meningkat dan langkahnya lahan pertanian yang subur dan potensial, serta adanya persaingan penggunaan lahan antara sektor pertanian dan non pertanian, memerlukan teknologi tepat guna dalam upaya mengoptimalkan penggunaan lahan secara berkelanjutan (Mulyani et al, 2011). Untuk dapat 
memanfaatkan sumberdaya lahan secara optimal, terarah dan efisien tersebut diperlukan data dan informasi mengenai tanah, iklim dan sifat fisik lingkungan lainnya, serta persyaratan tumbuh tanaman, terutama tanaman-tanaman yang mempunyai peluang pasar dan memiliki arti ekonomi cukup baik (Nurdin, 2010).

Data tanah, iklim dan sifat fisik lingkungan yang berpengaruh terhadap pertumbuhan tanaman serta aspek manajemennya perlu diidentifikasi dan dikarakterisasi melalui kegiatan survei dan pemetaan sumberdaya lahan. Data yang dihasilkan, selanjutnya diinterpretasi untuk tujuan penggunaan tertentu. Hasil penilaian memberikan informasi potensi atau arahan penggunaan lahan serta harapan produksi yang mungkin diperoleh (Ritung et al 2011).

Perlu suatu perencanaan matang dan tepat dalam mengambil keputusan pengembangan lahan yang sesuai dengan kriteria sehingga didapatkan hasil atau produksi optimal. Perencanaan dan pengambilan keputusan yang tepat harus dilandasi oleh data dan informasi akurat tentang kondisi lahan (Jayanti et al, 2013)

Tanaman vanili memiliki daya tarik yang cukup besar, dikarenakan nilai ekonominya yang cukup tinggi (Rosman, 2005). Secara fisik suatu lahan dikategorikan berpotensi untuk pengembangan tanaman vanili, jika kondisi lokasi tersebut memenuhi sebagian dari kriteria tanaman vanili. Desa Mamping kecamatan Balantak memiliki luas lahan yang cukup potensial untuk pengembangan tanaman vanili. Penelitian ini bertujuan untuk mengetahui karakteristik dan kesesuaian lahan serta faktor pembatas penggunaan lahan dalam pengembangan tanaman vanili (Vanilla planifolia) di Desa Mamping Kecamatan Balantak.

\section{METODE PENELITIAN}

Penelitian ini dilaksanakan di Desa Mamping Kecamatan Balantak. Waktu penelitian akan mulai November sampai dengan selesai. Variabel yang di amati dalam penelitian yakni Karakteristik dan kesesuian lahan terhdap pengembangan tanaman Vanili (Vanilla planifolia) berupa : Sifat fisik (Tekstur, Struktur,
Warna, Drainase) dan Sifat kimia, $\left(\mathrm{pH} \mathrm{H}_{2} \mathrm{O}\right.$, COrganik, KTK, Mg, K, Na, Fe, N total, $\mathrm{P}_{2} \mathrm{O}_{5}$ tersedia, $\mathrm{K}_{2} \mathrm{O}$ ).

Informasi kemiringan dan arah lereng sangat diperlukan bagi pengelolaan lahan. Klasifikasi Kelas Kelerengan, Panjang Lereng dan Bentuk Lereng disajikan dibawah ini.

Tabel 1. Klasifikasi Kelas Kelerengan, Panjang Lereng dan Bentuk Lereng.

\begin{tabular}{cc}
\hline Klasifikasi & Klasifiksi Bentuk \\
Kelerengan & Lereng \\
\hline $0-8 \%=1$ & Datar \\
$8-15 \%=2$ & Landai \\
$15-25 \%=3$ & Agak curam \\
$25-45 \%=4$ & Curam \\
$>45 \%=5$ & Sangat curam \\
\hline
\end{tabular}

Sumber : Syah \& Hariyanto (2013)

Analisis ksesuaian lahan berdasarkan pendekatan parametrik. Nilai lahan (NL) dihitung berdasarkan metode indeks lahan menurut Storie (1985).

$$
\mathbf{S}=\mathbf{A} \times \mathbf{B} \times \mathbf{C} \times \mathbf{X n}
$$

Dimana: $\mathrm{S}=$ indeks lahan Storie, $\mathrm{A}=$ sifat-sifat profil tanah, $\mathrm{B}=$ tekstur tanah permukaan $(0-30$ $\mathrm{cm}), \mathrm{C}=$ lereng, dan $\mathrm{Xn}=$ faktor lain yang dipertimbangkan (tingkat kesuburan tanah, drainase, dan erosi tanah). Penentuan nilai lahan merujuk pada O'geen et al (2008).

Penentuan kelas kesesuaian lahan merujuk pada Katili (2014) yaitu sebagai berikut:

1. Kelas 1 (baik sekali): tanah-tanah yang mempunyai nilai 80-100 \% cocok untuk pengunaan yang luas,seperti alfalfa,buahbuahan, dan field crops.

2. Kelas 2 (baik): tanah-tanah yang mempunyai nilai antara 60-79 \% cocok untuk sebagian besar tanaman. Hasil umumnya baik hingga baik sekali.

3. Kelas 3 (sedang): tanah - tanah yang mempunyai nilai antara 40-59 \% umumnya mempunyai kualitas sedang dengan kisaran penggunaan atau kesesuain lebih sempit dari pada kelas 1 dan 2. Tanah dalam kelas ini mungkin dapat memberikan hasil yang baik untuk tanaman tertentu. 
4. Kelas 4 (miskin): tanah -tanah yang mempumyai nilai antara 20-39 \% mempunyai kisaran/kemungkinan penggunaan pertanian yang terbatas. Sebagi contoh, tanah yang termasuk kelas ini mungkin baik untuk padi tetapi kurang baik untuk penggunaan lainnya.

5. Kelas 5 (sangat miiskin): tanah yang mempunyai nilai antara 10-19\%. Mempunyai kemungkinan penggunaan yang sangat terbatas, kecuali untuk padangrumput, karena kondisi - kondisi yang membatasi, seperti kedangkalan tanah.

6. Kelas 6 (bukan untuk pertanian): tanah yang mempunyai nilai kurang dari $10 \%$. Sebagai contoh, tanah pasang surut; tanah dengan kadarbasa - basa tinggi; dan tanah dengan lereng yang curam.

\section{HASIL DAN PEMBAHASAN}

\section{a. Morfologi dan Sifat Fisik Tanah}

Pedon Profil 1, terletak pada toposekuen bukit bagian atas dengan capaian kemiringan lereng $\geq 30 \%$, dalam petunjuk teknis evaluasi kesesuaian lahan pada kemiringan ini masuk klasifikasi bentuk lereng (curam), selanjutnya Profil 2, terletak pada toposekuen lereng bagian bawah dengan kemiringan lereng $>13$ $\%$,kemiringan tersebut masuk kategori (agak curam) atau sesuai marginal, pada klasifikasi bentuk lereng. Serta Profil 3, terletak pada kemiringan lereng $2 \%$ dengan toposkuen lereng bagian bawah kategori datar.

Tabel 2. Sifat Morfologi dan sifat Fisik Desa Mamping Kecamatan Balantak

\begin{tabular}{|c|c|c|c|c|c|c|c|c|c|c|}
\hline \multirow{2}{*}{ Horison } & \multirow{2}{*}{$\begin{array}{l}\text { Kedalaman } \\
(\mathrm{cm})\end{array}$} & \multirow{2}{*}{$\begin{array}{c}\text { Warna } \\
\text { matriks }\end{array}$} & \multirow{2}{*}{$\begin{array}{c}\text { Batas } \\
\text { horison }\end{array}$} & \multirow{2}{*}{ Struktur } & \multirow{2}{*}{ Konsistensi } & \multicolumn{3}{|c|}{ Tekstur tanah } & \multirow{2}{*}{ Kelas tekstur } & \multirow{2}{*}{$\begin{array}{c}\text { Kelas ukuran } \\
\text { butir }\end{array}$} \\
\hline & & & & & & Pasir & Debu & Liat & & \\
\hline \multicolumn{11}{|l|}{ Profil 1} \\
\hline Horison A & $0-13$ & 5 YR 3/4 & cs & Prisma & $\mathrm{S}$ & 33 & 48 & 19 & Lempung & Sedang \\
\hline Horison B & $13-36$ & $10 \mathrm{YR} 5 / 4$ & gs & Prisma & Ss & 26 & 42 & 32 & Lempung berliat & Agak Halus \\
\hline Horison $\mathrm{C}$ & $36-63$ & $10 \mathrm{YR} 5 / 3$ & gs & Prisma & Ss & 18 & 46 & 36 & Lempung berliat & Agak Halus \\
\hline BC & $>63$ & $10 \mathrm{YR} 5 / 3$ & ds & Prisma & $\mathrm{S}$ & 31 & 46 & 23 & Lempung & Sedang \\
\hline \multicolumn{11}{|l|}{ Profil 2} \\
\hline Horison $\mathrm{O}$ & $0-12$ & $10 \mathrm{YR} 4 / 1$ & cs & $a b$ & Ss & 38 & 29 & 33 & Lempung berliat & Agak Halus \\
\hline Horison A & Dec-32 & $10 \mathrm{YR} 5 / 2$ & cs & $a b$ & $\mathrm{~S}$ & 26 & 32 & 42 & Liat & Sangat Halus \\
\hline Horison E & $32-51$ & $10 \mathrm{YR} 4 / 2$ & gs & $a b$ & S & 30 & 26 & 44 & Liat & Sangat Halus \\
\hline Horison B & $51-84$ & $10 \mathrm{YR} 5 / 3$ & gs & $a b$ & $S$ & 32 & 18 & 50 & Liat & Sangat Halus \\
\hline Horison C & $84-102$ & $5 \mathrm{YR} 4 / 3$ & ds & $a b$ & S & 8 & 27 & 65 & Liat & Sangat Halus \\
\hline BC & $>102$ & $5 Y R 4 / 1$ & ds & $a b$ & $\mathrm{~S}$ & 17 & 43 & 40 & Liat berdebu & halus \\
\hline \multicolumn{11}{|l|}{ Profil 3} \\
\hline Horison A & $0-11$ & $10 \mathrm{YR} 4 / 2$ & cs & prisma & Ss & 20 & 61 & 19 & Lempung berdebu & Sedang \\
\hline Horison B & Nov-46 & $10 \mathrm{YR} 5 / 2$ & gs & prisma & Ss & 23 & 60 & 17 & Lempung berdebu & Sedang \\
\hline Horison C & $46-73$ & 10 YR 6/3 & ds & $a b$ & Ss & 18 & 62 & 20 & Lempung berdebu & Sedang \\
\hline $\mathrm{BC}$ & $>73$ & 10 YR 6/4 & ds & $a b$ & Ss & 12 & 67 & 21 & Lempung berdebu & Sedang \\
\hline
\end{tabular}

$\mathrm{ab}=$ gumpal bersudut; $\mathrm{sb}=$ gumpal; vs=sangat lekat; vf=sangat gembur; vp=sangat plastis; ss=agak lekat; so=tidak lekat; $\mathrm{s}=$ lekat; $\mathrm{t}=$ teguh; $\mathrm{f}=$ gembur; $\mathrm{p}=$ plastis; $\mathrm{cs}=$ jelas rata; $\mathrm{gs}=$ =erangsur rata; $\mathrm{ds}=$ baur nyata; $\mathrm{BC}=$ =bedrock

Pada kemiringan ini memungkinkan untuk pengembangan tanaman pertanian walaupun di dua profil $1 \& 2$ butuh pengolahan yang agak berat. Sejalan Ritung, et al, (2011), pada wilayah seperti ini membutuhkan pengolahan yang agak berat serta lahan yang agak sempit untuk tanaman tertentu. Sehinggahnya akan mempengaruhi produktivitasnya, maka perlunya pengolahan petani untuk meningkatkan produksinya (Wakiah et al, 2016). Selanjutnya, horison permukaan telah mendapat pengaruh pengolahan tanah. Ini penyebab para petani lebih intensif mengolah tanah jenis ini, dan pada pedon ini sudah menunjukkan perkembangan tanah dengan adanya strukturisasi (Nurdin, 2010).

Warna matriks tanah dengan hue 5YR dan 10 YR dengan variasi chroma dan value, profil 1 yaitu pada lapisan pertama hue 5 YR 3/4 (cokelat tua gelap), 10 YR 5/4 (coklat kekuningkuningan), 5/3 (coklat), dengan kedalaman $\geq 63$ $\mathrm{cm}$, yang menunjukkan terjadinya oksidasireduksi yang sering pada lapisan tanah tersebut. Profil 2, dengan warna matriks tanah dengan hue 10 YR 4/1 (abu-abu gelap), 5/2 (cokelat keabuabuan), 4/2 (coklat keabu-abuan agak gelap), 5/3 (coklat) dan 5YR 4/3 (coklat kemerahan) serta 
4/1 (abu-abu gelap) dari permukaan sampai pada kedalaman > $102 \mathrm{~cm}$. Serta Profil 3 warna matriks hue 10YR 4/2 (coklat keabu-abuan agak gelap), 5/2 (coklat keabu-abuan), 6/3 (cokelat pucat) dan 6/4 (coklat kekuningan) dari permukaan hingga $>73 \mathrm{~cm}$.

Selain itu juga, pada batas horison-horison ketiga profil 1,2 dan 3, nampak jelas berangsur rata dan berbaur nyata. Stuktur permukaan pada pedon ini (Prisma) karena sudah mengalami pengolahan tanah yang intensif. Selanjutnya profil 1, dengan Konsistensi sangat lekat (vs), lekat (s) serta agak lekat (ss) sebagai konsekuensi atas tekstur tanah yang berlempung dan lempung berliat dengan ukuran kelas butir sedang serta agak halus. Pada pedon ini tardapat banyak perakaran dan karatan dari lapisan paling atas sampai pada lapisan yang bawah terdapat

\section{Sifat Kimia Tanah}

Sifat kimia tanah (tabel 3), Pedon Profil-1, Profil 2 dan Profil 3,menunjukkan bahwa pada horison A dan berikutnya, dengan kandungan Corganik yang rendah sampai tinggi, yautu Profil1 berstatus rendah (1,90\%), Profil 2, bersatus tinggi (3.84 \%), serta Profil 3 dengan kandungan C-organik sedang $(2,61 \%)$, sementara pada atau dijumpai sedikit karatan. Profil 2, horison relatif jelas (cs) dan struktur tanah gumpal bersudut (ab) karena belum mengalami pengolahan tanah. Horizon-horison pedon ini mempunyai Konsistensi lekat (s), agak lekat (ss), sebagai konsekuensi atas tekstur tanah yang lempung berliat, liat dan liat berdebu dengan kelas ukuran butirnya yang sedang, agak halus serta halus, dan untuk profil 3, karatan tidak dijumpai pada semua lapisan, dan horison relatif jelas tara (cs) dan berangsur rata (gs), serta baur nyata (ds). Struktur tanah permukaan prisma dan horison selanjutnya berstruktur gumpal bersudut (ab). Konsistensi tidak lekat (so) dan agak lekat (ss) sebagai konsekuensi atas tekstur tanah Lempung berdebu dengan kelas ukuran butirnya yang horison di bawahnya justru menunjukkan semakin rendah. sejalan dengan Sipahutar et al, (2014); Wibisono et al, (2016) menyatakan bahwa C-organik pada umumnya cenderung tinggi di permukaan, di lapisan atas dan menurun seiring meningkatnya kedalaman tanah.

Tabel 3. Sifat kimia Tanah Desa Mamping, Kecamatan Balantak Kabupaten Banggai

\begin{tabular}{|c|c|c|c|c|c|c|c|c|}
\hline Horison & $\begin{array}{c}\text { Kedalaman } \\
(\mathrm{cm})\end{array}$ & $\begin{array}{c}\text { C-Organik } \\
(\%)\end{array}$ & $\begin{array}{c}\text { N-Total } \\
(\%)\end{array}$ & $\begin{array}{l}\mathrm{P}_{2} \mathrm{O}_{5} \\
(\mathrm{ppm})\end{array}$ & $\begin{array}{c}\text { K-Total } \\
\text { (ppm) }\end{array}$ & $\begin{array}{c}\mathrm{Na}^{+} \\
(\mathrm{me} / 100 \mathrm{~g})\end{array}$ & $\begin{array}{c}\mathrm{K}^{+} \\
(\mathrm{me} / 100 \mathrm{~g})\end{array}$ & $\begin{array}{c}\text { KTK } \\
(\mathrm{me} / 100 \mathrm{~g})\end{array}$ \\
\hline \multicolumn{9}{|l|}{ Profil 1 } \\
\hline Horison A & $0-13$ & 1.90 & 0.09 & 67 & 47 & 0.28 & 0.10 & 33.30 \\
\hline Horison $\mathrm{C}$ & $36-63$ & 1.01 & 0.07 & 72 & 41 & 0.36 & 0.09 & 36.90 \\
\hline BC & $>63$ & 0.45 & 0.11 & 66 & 42 & 0.30 & 0.09 & 26.03 \\
\hline Horison A & $12-32$ & 1.70 & 0.10 & 66 & 108 & 0.19 & 0.23 & 24.60 \\
\hline Horison E & $32-51$ & 1.75 & 0.12 & 67 & 134 & 0.24 & 0.29 & 31.71 \\
\hline Horison B & $51-84$ & 0.94 & 0.10 & 48 & 126 & 0.27 & 0.27 & 41.30 \\
\hline Horison $\mathrm{C}$ & $84-102$ & 0.79 & 0.11 & 70 & 101 & 0.45 & 0.22 & 32.82 \\
\hline BC & $>102$ & 0.55 & 0.10 & 67 & 84 & 0.11 & 0.18 & 34.07 \\
\hline \multicolumn{9}{|l|}{ Profil 3} \\
\hline BC & $>73$ & 0.51 & 0.12 & 69 & 84 & 0.30 & 0.18 & 26.07 \\
\hline
\end{tabular}

$\mathrm{KTK}=$ kapasitas tukar kation; ppm=part per million.

Demikian juga pada N-total ketiga profil ini dengan capaian kadar dan pola yang rendah. Maka perlunya suplai pupuk nitrogen untuk kecukupan dari bagi tanaman vanili pada masa vegetatif. Nitrogen mempunyai peran penting bagi pertumbuhan tanaman, diserap tanaman dari dalam tanah dalam bentuk NH4+ dan NO3-. N total merupakan unsur makro yang dibutuhkan tanaman dalam jumlah yang banyak dan 
menyusun $1.5 \%$ bobot tanaman (Gunawan et al, 2019). Unsur nitrogen merupakan unsur yang cepat kelihatan pengaruhnya terhadap tanaman, peran utama unsur ini adalah merangsang pertumbuhan batang dan daun (Tando, 2018). Ditambahkan oleh Nurholis et al, (2014) bahwa nitrogen sangat dibutuhkan untuk pertumbuhan dan peningkatan hasil tanaman.

Selanjutnya pada $\mathrm{P}_{2} \mathrm{O}_{5}$ Bray, Pedon Profil1 mencapai (67 ppm) Profil 2 mencapai (56 ppm) dan Pedon Profil 3 (65 ppm) maka, ketiga pedon tersebut dikategori sangat tinggi. Penilaian ini berdasarkan ketegori kriteria kesuburan tanah FAO (1983) bahwa kadar Ktotal dalam tanah pada Profil-1 Profil 2 dan profil 3, kadar K-total dalam tanah pada lapisan permukaan rendah sampai sedang, selanjutnya menurun dengan variasi ke lapisan lapisan kedua,tiga dan keempat. Namun setelah dirataratakan semua kandungan K-Total pada lapisan ini dalam kategori rendah. Sedangkan pada $\mathrm{Na}^{+}$

\section{Kelas Kesesuaian Lahan}

Berdasarkan Faktor dan nilai pada pedon pewakil (tabel 4), Profil-1, berdasarkan faktor sifat profil tanah (A) pada daerah tanah pada dataran tua (older plains ) atau pada teras yang mempunyai profil tanah yang sangat berkembang ( tanah bawah dengan liat yang padat ) Hal ini dapat dilihat atau di tunjukkan pada atribut dengan (kedalaman $>63 \mathrm{~cm}$ ). Kriteria berdasarkan faktor- faktor penentuan nilai lahan (NL) yang telah ditentukan dengan Storie index rating. Maka nilai lahan yang diperoleh $70 \%$ atau (0.70). Profil-2, profil tanah (A) pada daerah tanah pada dataran tua (older plains ) atau pada teras yang mempunyai profil tanah yang sangat berkembang ( tanah bawah dengan liat yang padat ) di tunjukan pada atribut dengan( kedalaman $102 \mathrm{~cm}$ ). Dengan nilai lahan yang diperoleh $80 \%$ atau (0.80). Profil -3 , berdasarkan faktor sifat profil tanah (A) pada daerah tanah pada dataran tua (older plains) atau pada teras yang mempunyai profil tanah yang sangat berkembang ( tanah bawah dengan liat yang padat). Hal ini dapat dilihat atau di tunjukan pada atribut dengan (kedalaman $>73$ dan $\mathrm{K}^{+}$sama halnya seperti pada profil-1, 2 dan 3 termasuk/tergolong rendah pada semua lapisan-lapisan dibawahnya. Disamping itu untuk KTK dapat digolongkan sedang sampai tinggi. Sebaran pola yang bervariasi terdapat pada basa-basa (Na, K dan KTK) sedangkan pada $\left(\mathrm{P}_{2} \mathrm{O}_{5}\right.$ Bray dan K-total) nampak jelas semakin ke lapisan bawah kadar sifat kimia tanah semakin menurun, dan pada C-organik dan $\mathrm{N}$-total juga nampak menurun pada lapisan bawahnya. Menurut Katili et al, (2015) bahwa kadar (Na, K dan KTK) reduksi-oksidasi sangat mempengaruhi basa-basa dapat ditukar dibandingkan sifat kimia lain $\left(\mathrm{P}_{2} \mathrm{O}_{5}\right.$, K-total, Corganik dan $\mathrm{N}$-total). Dari hasil diatas maka, perlunya suplai pupuk untuk pertumbuhan tanaman vanili di daerah penelitian. Sejalan dengan penelitian (Nurholis et al, 2014) dimana perlunya pemberian pupuk $\mathrm{N}, \mathrm{P}, \mathrm{K}$ agar dapat memenuhi ketersediaan nitrogen.

$\mathrm{cm}$ ) dengan nilai lahan yang diperoleh $80 \%$ atau (0.80).

Selanjutnya, berdasarkan nilai tekstur tanah lapisan atas (B) Profil 1 ini termasuk bertekstur Sedang (Lempung berpasir sangat halus ; lempung berpasir halus ; lempung ; lempung berdebu), sehingga diperoleh nilai lahannya sebesar 100\% atau (1.00), dan Profil 2, berdasarkan nilai tekstur tanah lapisan atas (B) pedon ini termasuk bertekstur Sedang (Lempung berliat), sehingga diperoleh nilai lahannya sebesar $85 \%$ atau (0.85). serta Profil 3, berdasarkan nilai tekstur tanah lapisan atas (B) pedon ini termasuk bertekstur Lempung berpasir sangat halus ; lempung berpasir halus ; lempung ; lempung berdebu, sehingga diperoleh nilai lahannya sebesar $100 \%$ atau (1.00).

Kemudian berdasarkan nilai kelerengan (slope) (C), Profil 1 ini termasuk pada kriteria lereng cukup Berbukit (hilly) dengan kemiringan (30\%) sehingga dapat diberi nilai sebesar $80 \%$ atau (0.80). Serta Profil 2 kelerengan (slope) (C), pada pedon ini termasuk dalam kriteria Cukup landai (Moderately sloping) ( $13 \%$ ) sehingga dapat diberi nilai sebesar $90 \%$ atau $(0,90)$. Berbeda dengan profil sebelumnya, profil 3 ini mempunyai nilai kelerengan (slope) (C), datar 
dengan kemiringan (2\%) sehingga dapat diberi nilai sebesar $100 \%$ atau (1.00).

Selanjutnya faktor lain pada profil 1 yang dipertimbangkan $(\mathrm{X})$ yaitu, terdiri dari Drainase, (berdrainase baik dengan nilai $80 \%$ atau 0.80 ), serta profil 2 dan profil 3, faktor lain yang dipertimbangkan (X) terdiri dari Drainase, (berdrainase baik dengan nilai $100 \%$ atau 1,00). Selanjutnya Pedon Profil 1, Profil 2 dan Profil 3 dengan tingkat kesuburan tanah (tinggi dengan nilai $95 \%$ atau 0.95 ). untuk tingkat kemasaman profil 1 dan profil 3, menurut tingkatnya dengan capaian nilai $80 \%(0,80)$. Serta Erosi tanah endapan merugikan (detrimental deposition) dengan nilai $75 \%$ atau $(0,75)$ kemudian pada profil 2 menurut tingkatnya dengan capaian nilai 85\% (0.85), dan erosi tanah profil ini dengan kriteria Erosi permukaan sedang dengan parit dangkal dengan nilai 80\% (0.80).

Berdasarkan hasil kelas kesesuaian lahan (tabel 5) yaitu Profil-1, Profil-2 dan Profil-3 dengan jumlah nilai lahan (NL) untuk semua faktor-faktor tanah (A, B, C dan X), maka ketiga pedon-pedon ini memperoleh nilai lahan masingmasing dengan hasil akhir dimana Profil-1 (46.2), Profil-2 (55.08) atau dilaporkan dalam Tabel 4. Faktor dan nilai lahan terhadap tiga pedon pewakil

\begin{tabular}{|c|c|c|c|c|c|c|}
\hline \multirow{2}{*}{ Faktor-Faktor Tanah } & \multicolumn{2}{|l|}{ Profil 1} & \multicolumn{2}{|c|}{$\begin{array}{l}\text { Pedon Pewakil } \\
\quad \text { Profil } 2 \\
\end{array}$} & \multicolumn{2}{|l|}{ Profil 3} \\
\hline & Atribut & $\begin{array}{l}\text { Nilai } \\
(\%)\end{array}$ & Atribut & $\begin{array}{c}\text { Nilai } \\
(\%)\end{array}$ & Atribut & Nilai (\%) \\
\hline \multicolumn{7}{|l|}{ A-Sifat Profil Tanah } \\
\hline $\begin{array}{l}\text { Tanah pada dataran tua (older } \\
\text { plains ) atau pada teras yang } \\
\text { mempunyai profil tanah yang } \\
\text { sangat berkembang ( tanah } \\
\text { bawah dengan liat yang padat) }\end{array}$ & $\begin{array}{l}\text { Kedalaman } \\
63 \mathrm{~cm}\end{array}$ & 70 & $\begin{array}{l}\text { Kedalaman } \\
102 \mathrm{~cm}\end{array}$ & 80 & $\begin{array}{l}\text { Kedalaman } \\
73 \mathrm{~cm}\end{array}$ & 80 \\
\hline \multicolumn{7}{|c|}{ B-Nilai Tekstur Tanah lapisan Atas } \\
\hline Bertekstur Sedang & $\begin{array}{l}\text { Lempung berpasir } \\
\text { sangat halus ; } \\
\text { lempung berpasir } \\
\text { halus ; lempung ; } \\
\text { lempung berdebu }\end{array}$ & 100 & Lempung berliat & 85 & $\begin{array}{l}\text { Lempung berpasir } \\
\text { sangat halus ; } \\
\text { lempung berpasir } \\
\text { halus ; lempung ; } \\
\text { lempung berdebu }\end{array}$ & 100 \\
\hline \multicolumn{7}{|l|}{ C-Nilai Kelerengan } \\
\hline Lereng (\%) & $\begin{array}{l}\text { Berbukit (Hilly) } \\
(30 \%)\end{array}$ & 80 & $\begin{array}{lr}\text { Cukup } & \text { landai } \\
\text { (Moderately } & \text { sloping) } \\
(13 \%) & \\
\end{array}$ & 90 & Hampir datar (2\%) & 100 \\
\hline \multicolumn{7}{|l|}{ X-Nilai Faktor Lain } \\
\hline Drainase & $\begin{array}{l}\text { Berdrainase agak } \\
\text { baik }\end{array}$ & 80 & Berdrainase baik & 100 & Berdrainase Baik & 100 \\
\hline Tingkat Kesuburan Tanah & sedang & 95 & Sedang & 95 & Sedang & 95 \\
\hline Kemasaman & Menurut tingkatnya & 80 & Menurut tingkatnya & 85 & Menurut tingkatnya & 80 \\
\hline Erosi Tanah & $\begin{array}{l}\text { Erosi permukaan } \\
\text { sedang dengan parit } \\
\text { dangkal }\end{array}$ & 75 & $\begin{array}{l}\text { Erosi permukaan } \\
\text { sedang dengan parit } \\
\text { dangkal }\end{array}$ & 80 & $\begin{array}{l}\text { Endapan merugikan } \\
\text { (detrimental } \\
\text { deposition) }\end{array}$ & 80 \\
\hline Total X & & 330 & & 360 & & 355 \\
\hline
\end{tabular}


90

88.7

Selanjutnya Bagu (2012) menjelaskan kesesuaian bentuk penggunaan lahan dianalisis secara kooparatif dengan membandingkan antara penggunaan lahan aktual saat ini dengan penggunaan lahan potensi masing-masing kelaskelas kemarnpuan lahan. Arahan pemanfaatan lahan dilandasi semangat rehabilitasi lahan untuk

konservasi tanah dan air dengan rnendasarkan potensi kelas kemampuan dan tekanan pendududuk (Senawi, 2006). Tetapi pada umumnya baik hingga baik sekali. Tanah jenis ini sangat baik untuk tanaman hortikultura (vanili) dengan pola yang teratur dan benar.

Tabel 5. Kelas Kesesuaian Lahan (KKL) Desa Mamping, Kecamatan Balantak

\begin{tabular}{lccc}
\multicolumn{1}{c}{ Faktor-Faktor Tanah } & \multicolumn{2}{c}{ Nilai Lahan Pedon Pewakil } & Profil-3 \\
\hline A-Sifat Profil Tanah (NL) & 0.70 & 0.80 & 0.80 \\
B-Nilai Tekstur Tanah lapisan Atas (NL) & 1.00 & 0.85 & 1.00 \\
C-Nilai Kelerengan (NL) & 0.80 & 0.90 & 1.00 \\
X-Nilai Faktor Lain & 82.5 & 90 & 88.7 \\
\hline Nilai (NL) Total & $\mathbf{0 . 5 6}$ & $\mathbf{0 . 6 1 2}$ & $\mathbf{0 , 8}$ \\
\hline Nilai Hasil Akhir & $\mathbf{4 6 . 2}$ & $\mathbf{5 5 . 0 8}$ & $\mathbf{7 0 . 9 6}$ \\
\hline Kelas Kesesuaian Lahan (KKL) & Kelas 3 (Sedang) & Kelas 3 (Sedang) & Kelas 2 (Baik)
\end{tabular}

\section{Faktor Pembatas Penggunaan Lahan}

Berdasarkan hasil analisis karakteristik dan kesesuaian lahan, maka ditentukan faktor pembatas penggunaan lahan yang dominan sebagai berikut: Profil-1, faktor pembatas yang mempengaruhi salah satu penggunaan lahan berkelanjutan adalah tekstur tanah lapisan atas yang tergolong bertekstur berat dan kurangnya kandungan bahan organik /rendah sehingga pada hal ini sangat mempengaruhi pengolahan tanah tersebut. Salah satu upaya yang dapat dilakukan adalah melakukan penambahan bahan organik agar struktur tanah menjadi baik serta dapat dilihat berdasarkan pada sifat kimia tanah yaitu kadar N-total dan K- total juga sangat rendah sampai sangat rendah, maka dari itu perlunya pemberian pupuk $\mathrm{N}$, K sesuai dengan yang dibutuhkan agar ketersediaan N, K tanah dapat terpenuhi dengan baik. Selain itu juga Lereng dan kedalaman efektif adalah faktor penghambat yang paling dominan membentuk sub kelas kemampuan dari suatu lahan (Fahimuddin et al, 2016).

Selanjutnya Pada profil-2, Sebagian besar lahan-lahan di wilayah penelitian untuk pengembangan tanaman Vanili memiliki kelas keseuaian lahan dengan faktor pembatas berat (S3= sesuai marginal) bahkan sampai sangat berat $(\mathrm{N}=$ tidak sesuai). Faktor-faktor pembatas tersebut meliputi media perakaran, retensi hara, dan drainase. Namun apabila diadakan pengelolaan yang disesuaikan dengan kondisi petani maka faktor yang masih membatasi penggunaan lahan adalah rata-rata curah hujan pertahun. Ini disebabkan tingginya kebutuhan air tanaman sedangkan rata-rata curah hujan rendah. Hal ini sangat mempengaruhi pengolahan tanah pada musim kering sementara pada musim hujan tanah menjadi sangat lekat karena kadar liat yang tinggi. Disamping itu dapat juga dilihat pada analisis sifaat kimia bahwa pada pedon ini kekurangan kadar baham organik, N-total, Ktotal dan hara lainnya dimana dalam kategori rendah sampai sangat rendah.

Selain itu, pada profil-3, yang mempengaruhi terbatas penggunaan lahan berkelanjutan adalah tekstur tanah lapisan atas yang tergolong sedang dan kurangnya kandungan bahan organik sehingga sangat mempengaruhi pengolahan tanah. Namun masalah ini bisa dipecahkan dengan cara pemupukan yang intensif dan sesuai dengan dosis atau takaran yang dianjurkan. dan salah satu upaya yang dapat dilakukan adalah melakukan penambahan bahan organik agar struktur tanah menjadi baik serta dapat dilihat berdasarkan pada sifat kimia tanah pedon ini mempunyai bahan rendah sampai sangat rendah, maka dari itu perlunya pemberian pupuk $\mathrm{N}$ dan $\mathrm{K}$ sesuai dengan yang dibutuhkan agar ketersediaan $\mathrm{N}$ dan $\mathrm{K}$ pada tanah dapat 
terpenuhi dengan baik. Serta pada pedon ini tidak perlu diberikan pupuk $\mathrm{P}$ karena terdapat kandungan $\mathrm{P}$ dengan kategori yang tinggi. Pada pedon ini tidak dapat di hindari lagi karena drainase tanah yang sangat buruk dan menjadi genangan air diwaktu musim hujan maka dalam hal ini kadar basa Natrium akan sangat tinggi. Tetapi pada profil ini agak berbeda dengan profil sebelumnya dimana nilai lahan-nya dalam kategori baik (kelas dua). Ini menandakan bahwa dalam olah tanah pada wilayah ini tidak semaksimal pada profil sebelumnya. Maka dengan hasil ketiga pedon diatas perlunya sentuhan masyrakat dalam pengelolaan lahan yang baik dan perlunya tatanan tata kelola suatu lahan berdasarkan tanaman yang diinginkan. Sejalan dengan pernyataan Bagu (2012) bahwa penggunaan lahan harus terencana khususnya pengaturan, pemanfaatan lahan sangat diperlukan. Apabila tidak dilakukan pengaturan akan mengakibatkan terjadinya ketidak seimbangan antara daya dukung lahan dengan potensi lahan untuk mendapatkan produksi yang diinginkan.

\section{KESIMPULAN}

Kelas kesesuaian lahan (KKL) untuk Profil-1, dan Profil-2 termasuk dalam kategori kelas 3 (sedang), maka hal ini dapat ditentukan untuk adanya tanaman vanili, walaupun masih membutuhkan pengelolaan lahannya (pemupukan) yang teratur. Pada profil-3 perlunya penataan dalam olah tanah agar menjaga kestabilan dari suatu lahan untuk tanaman vanili jangka panjang. Faktor pembatas untuk penggunaan lahan tanaman vanili di pedon (Profil-1, 2 dan 3) pada tanah lapisan atas yang bertekstur sedang dan kurangnya kandungan bahan organik, $\mathrm{N}$ dan K. Pada profil.3 bertekstur liat yang tinggi dan drainase tanah yang kurang baik.

\section{DAFTAR PUSTAKA}

Bagu FS. 2012. Model Spasial Ekologis untuk optimalisasi penggunaan lahan tanaman jagung (Zea mays L.) di Kabupaten Pohuwato - Provinsi Gorontalo. Disertasi. Universitas Gaja Mada. Yogyakarta.

Djaenudin D, Marwan H, Subagjo H, Hidayat A. 2011. Petunjuk teknis evaluasi lahan untuk komoditas pertanian. Balai Besar Litbang Sumberdaya Lahan Pertanian, Badan Litbang Pertanian, Bogor. 36p

Fahimuddin MM, Baba B.Barus B, Mulatsih S. 2016. Analisis daya dukung lahan di kota Bau-Bau Sulawesi Tenggara. Jurnal Tataloka. 18(3): 183-196.

FAO. 1983. Guidelines: Land evaluation for rainfed agriculture. FAO Soils Bulletin No. 52. Rome: Food and Agriculture Organization of the United Nations.

Jayanti DS, Goenadi S, Hadi P. 2013. Evaluasi kesesuaian lahan dan optimasi penggunaan lahan untuk pengembangan tanaman kakao (Theobroma cacao L.) (Studi kasus di Kecamatan Batee dan Kecamatan Padang Tiji Kabupaten Pidie Propinsi Aceh). Jurnal Agritech, 33(2): 208-218

Katili HAM, Nurdin, Pembengo W. 2015. Karakteristik dan kelas kesesuaian lahan untuk tanaman kentang (Solanum toberosum L.) di Desa Boloak Kabupaten Banggai. Jurnal Agroteknotropika, 4(3): 264-272

Mulyani A, Ritung S, Las I. 2011. Potensi dan ketersediaan sumber daya lahan untuk mendukung ketahanan pangan. Jurnal Litbang Pertanian, 30 (2): 73-80

Nurdin. 2010. Perkembangan, klasifikasi dan potensi tanah sawah tadah hujan dari bahan lakustrin Paguyaman, Gorontalo. Tesis. Institut Pertanian Bogor, Bogor

Nurholis, Hariyadi, Kurniawati A. 2014. Pertumbuhan bibit panili pada beberapa komposisi media tanam dan frekuensi aplikasi pupuk daun. Buletin Penelitian Tanaman Rempah dan Obat. 25 (1): 11-20

O'geen AT, Southard SB, \& Southard RJ. 2008. Revised Storie Index for Use with Digital Soils http://dx.doi.org/10.3733/ucanr.8335 Retrieved from https://escholarship.org/uc/item/8kq9s4wd 
Rehmamana R, Lanya I, Dibia IN. 2020. Aplikasi remote sensing dan geographic information system untuk perencanaan penggunaan lahan pertanian berbasis agroekosistem di Kota Denpasar. Jurnal Agroekoteknologi Tropika, 9(1): 32-42

Ritung S, Nugroho K, Mulyani A, Suryani E. 2011. Petunjuk teknis evaluasi lahan untuk komoditas pertanian. Edisi Revisi. Balai Besar Penelitian dan Pengembangan Sumberdaya Lahan Pertanian. Bogor. $166 \mathrm{hlm}$.

Ritung S, Wahyunto, Fahmuddin, Hidayat A. 2007. Panduan evaluasi kesesuaian lahan dengan contoh peta arahan penggunaan lahan Kabupaten Aceh Barat. Balai Penelitian Tanah dan World Agroforestry Centre (ICRAF), Bogor.

Rosman R. 2005. Status dan strategi pengembangan panili di Indonesia. Jurnal Perspektif, 4(2): 43-54.

Senawi. 2006. Analisis kemampuan dan daya dukung lahan untuk penatagunaan lahan subdas dengkeng DAS Bengawan Solo Majalah Geografi Indonesia. 20(2):137-151.

Sipahutar AH, Marbun P, Fauzi. 2014. Kajian C-organik, $\mathrm{N}$ dan $\mathrm{P}$ humitropepts pada ketinggian tempat yang berbeda di Kecamatan Lintong Nihuta. Jurnal Online Agroekoteknologi, 2(4): 13321338

Syah MW \& Hariyanto T. 2013. Klasifikasi kemiringan lereng dengan menggunakan pengembangan sisten informasi geografis sebagai evaluasi kesesuaian lahan pemukiman berdasarkan undang-undang tata ruang dan metode Fuzzy. Jurnal Teknik Pomits. 10(10): 1-6

Tando E. 2018. Upaya efisiensi dan peningkatan ketersediaan nitrogen dalam tanah serta serapan nitrogen pada tanaman padi sawah (Oryza sativa L.). Buana Sains, 18(2): 171-180
Wakiah S, Rombang JA, Rogi JEX. 2016. Evalusai lahan untuk pengembangan lahan perkebunan di pulau Bacan Kabupaten Halmahera Selatan. Jurnal Agri-Sosio Ekonomi, 12 (2a): 377-382

Wibisono MG, Sudarsono, Darmawan. 2016. Karakteristik andisol berbahan induk breksi dan lahar dari bagian timur laut Gunung Gede, Jawa Barat. Jurnal Tanah dan Iklim, 40(1): 61-70

Widiatmaka. 2012. Perkembangan dan permasalahan dalam survei tanah dan evaluasi lahan di Indonesia. Prosiding Seminar internasional dan forum ilmiah tahunan ikatan surveyor Indonesia. Jakarta, 17 Oktober 2012, 137-142. 